Article

\title{
Spatio-Temporal Changes in Vegetation Activity and Its Driving Factors during the Growing Season in China from 1982 to 2011
}

\author{
Bo Qu ${ }^{1,2}$, Wenbin Zhu ${ }^{1}$, Shaofeng Jia ${ }^{1}$ and Aifeng $\operatorname{Lv}{ }^{1, *}$
}

1 Key Laboratory of Water Cycle and Related Land Surface Processes, Institute of Geographic Sciences and Natural Resources Research, Chinese Academy of Sciences, Beijing 100101, China; E-Mails: geo_qb@163.com (B.Q.); bfdh198612@163.com (W.Z.); jiasf@igsnrr.ac.cn (S.F.);

2 University of Chinese Academy of Sciences, Beijing 100049, China

* Author to whom correspondence should be addressed; E-Mail: 1vaf@ 163.com; Tel.: +86-010-6485-6539; Fax: +86-010-6485-6539.

Academic Editors: Dengsheng Lu, Guomo Zhou, Conghe Song, Guangxing Wang and Prasad S. Thenkabail

Received: 5 August 2015 / Accepted: 10 October 2015 / Published: 21 October 2015

\begin{abstract}
Using National Oceanographic and Atmospheric Administration/Advanced Very High Resolution Radiometer (NOAA/AVHRR) and Climatic Research Unit (CRU) climate datasets, we analyzed interannual trends in the growing-season Normalized Difference Vegetation Index (NDVI) in China from 1982 to 2011, as well as the effects of climatic variables and human activities on vegetation variation. Growing-season (period between the onset and end of plant growth) NDVI significantly increased $(p<0.01)$ on a national scale and showed positive trends in $52.76 \%$ of the study area. A multiple regression model was used to investigate the response of vegetation to climatic factors during recent and previous time intervals. The interactions between growing-season NDVI and climatic variables were more complex than expected, and a lag existed between climatic factors and their effects on NDVI. The regression residuals were used to show that over $6 \%$ of the study area experienced significantly human-induced vegetation variations $(p<0.05)$. These regions were mostly located in densely populated, reclaimed agriculture, afforestation, and conservation areas. Similar conclusions were drawn based on land-use change over the study period.
\end{abstract}


Keywords: GIMMS NDVI; multiple regression; climate change; human activities; trend analysis

\section{Introduction}

Vegetation is a critical component of terrestrial ecosystems and plays an important role in the climate system [1]. Vegetation helps maintain climate stability through various processes such as photosynthesis, evapotranspiration, modifying surface albedo and roughness, and regulating the global carbon cycle [2,3]. However, according to recent studies, there is high confidence that rapid changes in vegetation cover are occurring [4-8], and these alterations can significantly influence the coupling of the earth and atmosphere [9]. As a result, considerable interest has been focused on investigating the spatio-temporal changes in vegetation activity and its driving factors.

Although field surveys can generate accurate information related to vegetation dynamics, studies on spatio-temporal changes in vegetation activity are usually conducted based on remote sensing technology, which is very efficient and provides high spatial and temporal resolution [6,10]. Among various remotely sensed vegetation indices, the Normalized Difference Vegetation Index (NDVI) has been shown to be a sensitive indicator of terrestrial vegetation activities. There are several NDVI datasets derived from different satellites, but the dataset derived from National Oceanic and Atmospheric Administration's (NOAA) Advanced Very High Resolution Radiometer (AVHRR) has been widely used to monitor vegetation activities on regional [7,11-13] to global scales [5,6,14]. For example, in China, many studies had been conducted to analyze the interannual trends in vegetation based on the NOAA-AVHRR NDVI [15-18]. However, these studies were mainly focused on either annual or seasonal NDVI variations. The spatio-temporal changes in NDVI during the growing season, when vegetation activities are mostly manifested, have not been adequately quantified.

As numerous studies have revealed, climate variation is one of the main drivers of interannual variations in vegetation activity [5,14,19-21]. In China, variations in temperature and precipitation have been observed to influence vegetation activities, and the relationships between NDVI and climatic factors have been investigated on regional and national scales [17,18,22-24]. However, in most of these studies, the response of vegetation to climate variations was analyzed by relating NDVI with precipitation and temperature to find the best correlations for a given period at seasonal and annual time scales. Although such correlations assist in understanding the impacts of climate change on vegetation dynamics and shed light on the mechanisms controlling changes in vegetation activities [22], it is difficult to distinguish the effects of individual climatic parameters and identify how vegetation responds to the combined effects of multiple factors [25]. For example, in arid regions, increased precipitation is beneficial to plant growth, but higher temperature leads to stronger photosynthetic activity as well as increased evaporation [21,22,26-29]. As a result, some confusion will arise from using a simple correlation analysis to compare different climatic factors, especially those from previous periods. In fact, it is usually necessary to include parameters from previous periods in climate models because of the time lag between climatic factors and their effects on NDVI [10,25,26,30]. Therefore, a comprehensive study is needed to further investigate the combined effects of climatic factors while fully considering the lag effect of climate variations. 
In addition to climate variations, anthropogenic activities (e.g., urbanization, ecological management and restoration, (over)grazing, and cropping) are also expected to influence vegetation activity variations. For example, in some areas such as densely populated areas [31] and drylands [32-34], human-induced disturbances have been regularly cited as one of the principal causes of changes in vegetation cover. In Inner Mongolia, human factors such as population growth and city expansion were found have a greater influence on vegetation degradation than climatic changes from 2000 to 2012, and ecological restoration programs also played a large role in vegetation improvement [35]. With the rapid development of society and economy over the past three decades, dramatic changes in land use and land cover have occurred in China [36]. These changes are mainly reflected in the following two aspects. (1) The urbanization rate in China has increased from $20 \%$ in 1980 to $51.3 \%$ in 2011, resulting in a huge transformation of cultivated land into building land. (2) A series of ecological management and restoration projects such as the Three-North Shelter Forest Program (TNSFP) have been initiated to combat environmental degradation. Over the same period, agricultural yield greatly improved in China. To fulfill increased demand from population growth, urbanization, and industrialization, numerous agricultural practices such as irrigation and fertilization were implemented in croplands [37]. These agricultural practices also influenced vegetation activities over some regions, especially in the Northeast China Plain and North China Plain. Although the impacts of these anthropogenic activities on vegetation changes have been discussed in several studies [17,18,38], these investigations were merely based on NDVI time series and could not provide a clear conclusion as to whether changes in vegetation activities are mainly caused by climate change or anthropogenic activities [39]. A number of studies have attempted to further investigate human impacts on vegetation activity variations based on differences between remotely sensed and model-predicted NDVI [40-42] have provided a foundation for quantitative research on human-induced vegetation activity variations in China.

In summary, the spatio-temporal changes in vegetation activities and its driving factors in China need further research in three major areas: (1) the spatio-temporal changes in vegetation activities during regional growing seasons using the most recent GIMMS NDVI dataset; (2) the driving forces of vegetation activities; and (3) human-induced influences on vegetation activities. According to these guidelines, an empirical algorithm was first used to determine the growing season in China, and the linear trend of the average NDVI during the growing season was analyzed. Second, a multiple regression (MR) model was applied to characterize the climatic controls on vegetation activities. Model residuals provide an excellent explanation of climatic effects on growing-season NDVI variations, and thus an opportunity to detect human-induced influences on vegetation activities [41,42]. Third, the linear trend of the model residuals was analyzed to extract the human-induced component of the total NDVI variations and a validation of the combined effects of climate variations and anthropogenic activities was conducted using land-cover data.

\section{Materials}

\subsection{NOAA AVHRR NDVI}

The NOAA-AVHRR NDVI dataset from January 1982 to December 2011 was used in our study. The latest version of the GIMMS NDVI dataset (termed NDVI3g), with an 8-km spatial resolution and 
15-day interval, has accounted for various deleterious effects in previous studies, such as calibration loss, orbital drift, and volcanic eruptions [43].

Although this dataset has been successfully used in numerous studies, residual noise always remains, even after applying strict preprocessing procedures, and thus impedes further analysis [44,45]. A number of methods have been applied to reduce residual noise, such as the fast Fourier transform technique [46], asymmetric Gaussian function-fitting method [47], and weighted least-squares linear regression approach [48]. In 2004, Chen et al. developed a simple but robust method based on the assumption that NDVI time series follow annual cycles of growth and vegetation decline [44]. As this technique greatly improved the NDVI values depressed by clouds or poor atmospheric conditions, we used it to construct a high-quality NDVI time-series. First, a linear interpolation was applied to cloudy NDVI values. Then, using the Savitzky-Golay filter to fit the NDVI variations, the upper NDVI envelope was calculated through an iteration process to generate a new NDVI time series. The Savitzky-Golay filter applies an iterative moving average filter to data, with weighting given as a polynomial of a particular degree. Using the general formula:

$$
\tilde{X}_{j}=\frac{\sum_{i=-m}^{i=m} C_{i} X_{j+i}}{N}
$$

Where $X$ is the NDVI time series, $\tilde{X}$ is the smoothed result, $C$ is a coefficient matrix of the filter, and $N$ is the size of smoothing window $(2 m+1)$. For each computation (generating a new $j$ th NDVI value of time series), the smoothing array centered at the $j$ th NDVI value consists of $2 m+1$ NDVI values, and the coefficients $\left(C_{i}\right)$ can be obtained directly from Savitzky and Golay's work [35]. The smoothing window $(N)$ and the degree of the smoothing polynomial, which determine the coefficient matrix of the filter, are selected as the set of 9 and 6, respectively [44].

\subsection{Climate Data}

Because of its long time scale and reliable derivation method [49], climate data from the Climatic Research Unit (CRU) have been widely used in many studies at global [50,51] and regional scales [21], as well as in China [17,23]. This dataset covers the period from 1901 to the present and is available from the University of East Anglia (http://www.cru.uea.ac.uk/). The temperature and precipitation data in our study were also derived from this global grid dataset. Generally, the $0.5^{\circ}$ degree climate dataset is resampled at $1 / 12^{\circ}$ to spatially match the NDVI dataset [8,21]. Furthermore, we used the cubic convolution method to improve the quality of the interpolation [52].

\subsection{Land-Cover Data}

The land-cover data were derived from Landsat TM/ETM data, with a spatial resolution of $1 \mathrm{~km}$. The land-cover 25 classes were further grouped into six aggregated classes including croplands, woodlands, grasslands, water bodies, unused land, and built-up areas [53]. The classification system is shown in Table 1. According to previous evaluation, the overall accuracy of the land-cover classification was above $90 \%$ [53]. 
Table 1. Classification system of land-cover data.

\begin{tabular}{cl}
\hline 1st Level Classes & \multicolumn{1}{c}{ 2nd Level Classes } \\
\hline Cropland & Paddy and dry farming land \\
\hline Woodland & Forest, shrub, woods and others (e.g., orchards, tea-garden) \\
\hline Grassland & Dense, moderate and sparse grass \\
\hline Water body & $\begin{array}{l}\text { Stream and rivers, lakes, reservoir, ponds, permanent ice and snow, beach and } \\
\text { shore, and bottomland }\end{array}$ \\
\hline Built-up land & $\begin{array}{l}\text { Urban area, rural settlements and others } \\
\text { (e.g., factories, mining) }\end{array}$ \\
\hline Unused land & $\begin{array}{l}\text { Sandy land, Gobi, Salina, wetland, bare soil, bare rock and others (e.g., alpine } \\
\text { desert, tundra) }\end{array}$ \\
\hline
\end{tabular}

\section{Methods}

\subsection{Extraction of Phenological Parameters}

Satellite-observed phenology is closely related to seasonal vegetation dynamics, although it is not identical to plant phenology [39,54]. Various algorithms have been described to detect the start date or end date of the growing season (e.g., the delayed moving average method (DMA) [54], Weibull curve approach [4], HANTS-FFT method [46], Quadratic method [55], NDVI threshold [56], and so on).

In 1997, Moulin et al. proposed a method to derive the start, end, and length of the vegetative cycle. Compared to complex mathematical methods such as DMA, Weibull Curve, and HANTS-FFT, the method by Moulin et al., which is directly derived from NDVI series, is simpler and easier. With this method, they successfully assessed the main phenological stages of vegetation on a global scale and discussed global zonal distributions and vegetation class performance [57]. As the NDVI threshold is usually set as a constant, it may not be appropriate in China where vegetation distribution is extremely complex. Therefore, in this paper, following Moulin et al. (1997), an empirical algorithm was applied to extract vegetative phenological stages in China. In this algorithm, the start date of the growing season is defined as the minimum date of series $b_{i}$, and the end date is defined as minimum date of series $e_{i}$.

$$
\begin{aligned}
& b_{i}=\left|x_{i}-x_{0}\right|-\lambda\left[\left(x_{i+2}-x_{i}\right)-\left|x_{i-2}-x_{i}\right|\right] \\
& e_{i}=\left|x_{i}-x_{0}\right|-\gamma\left[\left(x_{i+2}-x_{i}\right)-\left|x_{i-2}-x_{i}\right|\right]
\end{aligned}
$$

where $x_{i}, x_{i+2}, x_{i-2}$ is the NDVI value for dates $i, i+2$, and $i-2$ and $x_{0}$, which is referred to as the soil threshold, is set to the lowest value of the yearly NDVI series. The coefficients $\lambda$ and $\gamma$ weight the derivative term of the equation and are set to 3 and 5 , respectively.

In China, the growing season for natural vegetation is mainly between March and November [16,58]. For crops, the growing season is very complicated due to various cropping systems and frequent crop rotations. In this study, to simplify this issue, we assumed that the cropping system and planted crops did not change in the same land over the past three decades. When extracting phenological parameters, we assumed the length of growing season was from the green-up date of the earliest crop to the harvesting date of the last crop in one year. As the algorithm in this study was based on the rate of change of the NDVI time series, it could result in anomalies when used to monitor plants with multiple growing seasons. Therefore, the algorithm should be modified in such situations. 
Generally, in regions with double cropping systems, the typical maturity date of the first crop (e.g., wheat and early rice) is between June and July, and the next crop (e.g., maize and late rice) is planted after a short break [59,60]. Therefore, in this study, the start and end dates were calculated with a minimum of $b_{i}$ before June and a minimum of $e_{i}$ after July, respectively.

\subsection{Linear Trend Analysis}

To analyze trends in the NDVI time-series during the growing season, the least-square linear regression model was applied:

$$
y_{t}=a t+b
$$

where $y_{t}$ describes the NDVI time-series; $t$ is the time vector; and $a$ and $b$ represent the intercept and slope of the regression model, respectively. A t-test was used to estimate the significance of the regression. Areas with little or no vegetation (yearly average NDVI below 0.1 ) were masked in this study $[39,40]$.

Because of the large climate range and complex topography throughout China, the entire area was divided into eight sub-regions for further analysis (Figure 1). Northeast China (A1), Southwest China (A5), North China (A6), the Middle to Lower Reaches of the Yangtze River (A7), and South China (A8) represent typical monsoon regions, whereas the sub-regions of Inner Mongolia (A2) and Northwest China (A3) are located in arid and sub-arid regions. The Tibetan Plateau (A4), a special alpine-cold zone, is an independent region.

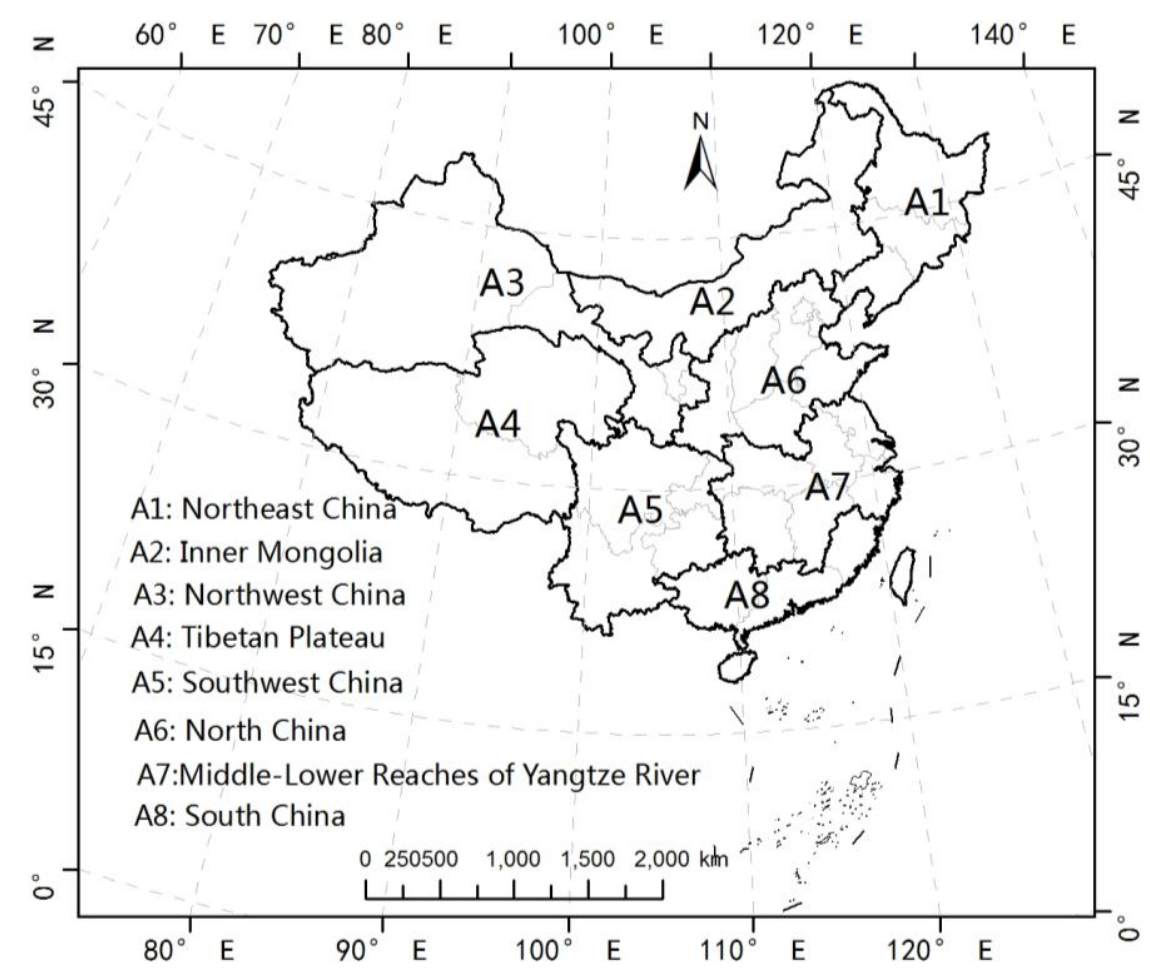

Figure 1. Spatial distribution of regions A1-A8 in China (Taiwan Island and Hainan Island belong to A8). 


\subsection{Multiple Regression Model of the NDVI-Climate Relationship}

Owing to lag effects and interactions among variables, climatic factors are related to vegetation activities in more complex ways than previously proposed [5,25]. Some earlier studies have attempted to reveal these unpredictable relationships. For example, a lagged of about 2 years was found in the correlation between NDVI and temperature on a global scale [10], and these results were supported by Los et al. [6]. Regionally, the lag time varies from a few months to several years [25,26,30]. In China, a lag response of about 3 months exists between NDVI and climate change [18]. On the basis of these studies, a period of about 2 years, which includes the current and previous growing seasons and the withering season, was used in our investigation (Figure 2).

To investigate more complex relationships, this period should be divided into stages. First, the growing season of the previous year is an important stage within the 2-year time interval. Second, contemporaneous temperature and precipitation have been highlighted in many studies, and thus the growing season of the current year should be separated. Third, based on Piao [18], we divided the withering season into two sections, three months before the current growing season and the remaining period. These four stages of deciduous broadleaf forests are described in Figure 2.

We used multiple linear regression analyses to derive the comprehensive relationships between growing-season NDVI and climatic factors. The mean temperature and total precipitation during all stages were selected as independent variables to explain the variation in growing-season NDVI.

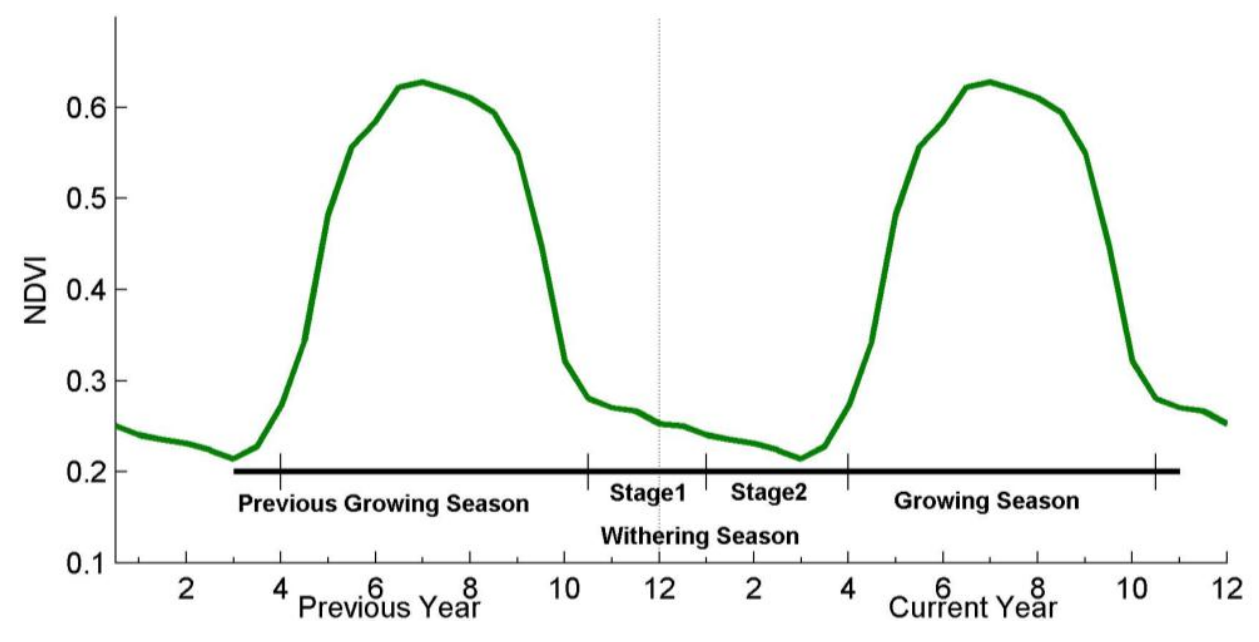

Figure 2. Periods of vegetation cycle (showed by NDVI variation of deciduous broadleaf forests in North China).

A general mathematical formula for the multiple linear regression model is described in Equation (4):

$$
y=f(x, \phi)+\varepsilon
$$

where $y$ represents the NDVI time series, $x$ represents the temperature and precipitation time series, $\phi$ is a fitting coefficient, and $\varepsilon$ is the residual series between actual and predicted NDVI.

To compare the influences of independent variables on growing-season NDVI, each series of independent variables was normalized by subtracting the mean of the time series and dividing by the standard deviation [61]. Among the multiple regression coefficients obtained with the normalized data, 
variables with the largest coefficients were considered to best explain NDVI. Typically, the root mean squared error (RMSE) and its percentage are calculated to assess the accuracy of multiple regression models.

\subsection{Model Residuals and Detection of the Contribution of Human Activities}

Generally, the residuals from multiple regression models reveal anomalies in the dependent variables that cannot be explained by the independent variables. Therefore, the residuals of the NDVI model can provide information on human-induced vegetation variations, as well as other disturbances. A series of previous articles have focused on this issue and found that simple linear regressions of model residuals can reveal the contributions of human activities to vegetation growth [32,40-42]. Negative slopes generally imply decreasing vegetation cover, whereas positive values suggest the opposite [32,41]. Contemporary land-cover data can be useful for explaining the validity of a model. In this paper, land-cover data from 1990 and 2005 were used to detect changes in land use and were compared with growing-season NDVI from 1982 to 2011.

\section{Results and Discussion}

\subsection{Spatio-Temporal Changes in Growing-Season NDVI}

Table 2 describes the trends of growing-season NDVI in each sub-region. In China, growing-season NDVI exhibited a significant increase $(p<0.01)$ of $0.0004 \mathrm{yr}^{-1}$ from 1982 to 2011, and positive trends were measured in $52.76 \%$ of the study area. Furthermore, $21.22 \%$ of the study area significantly increased $(p<0.05)$, whereas $5.68 \%$ significantly decreased $(p<0.05)$. As shown in Table 2, positive trends were found in all sub-regions except Inner Mongolia (A2) from 1982 to 2011, and the trends were strongest in Northwest China (A3), North China (A6), and South China (A8) $(p<0.01)$.

Table 2. Growing-season Normalized Difference Vegetation Index (NDVI) trends from 1982 to 2011 in sub-regions and whole China.

\begin{tabular}{|c|c|c|c|c|c|c|c|c|c|}
\hline \multirow[b]{2}{*}{ Region } & \multirow[b]{2}{*}{$\begin{array}{c}\text { Average } \\
\text { Slope } \\
\left(\mathbf{1 0}^{-3}\right)\end{array}$} & \multicolumn{5}{|c|}{ Slope } & \multicolumn{3}{|c|}{ T-Test } \\
\hline & & $<-0.002$ & $<0$ & $\mathbf{0}$ & $>0$ & $>0.002$ & $\begin{array}{c}\text { Significant } \\
\text { Decrease } \\
(p<0.05)\end{array}$ & $\begin{array}{c}\text { Significant } \\
\text { Increase } \\
(p<0.05)\end{array}$ & $\begin{array}{c}\text { No } \\
\text { Significance }\end{array}$ \\
\hline Northeast China (A1) & 0.22 & $5.85 \%$ & $45.33 \%$ & $0.00 \%$ & $54.73 \%$ & $9.51 \%$ & $9.81 \%$ & $14.47 \%$ & $75.72 \%$ \\
\hline Inner Mongolia (A2) & -0.18 & $6.09 \%$ & $44.00 \%$ & $20.54 \%$ & $35.48 \%$ & $2.15 \%$ & $12.20 \%$ & $10.02 \%$ & $77.78 \%$ \\
\hline Northwest China (A3) & $0.18 * *$ & $2.69 \%$ & $16.14 \%$ & $54.23 \%$ & $29.63 \%$ & $5.02 \%$ & $6.78 \%$ & $21.53 \%$ & $71.69 \%$ \\
\hline Tibetan Plateau (A4) & 0.18 & $2.11 \%$ & $27.36 \%$ & $28.26 \%$ & $44.45 \%$ & $3.65 \%$ & $4.17 \%$ & $12.13 \%$ & $83.70 \%$ \\
\hline Southwest China (A5) & 0.79 & $1.58 \%$ & $25.76 \%$ & $0.00 \%$ & $74.24 \%$ & $16.35 \%$ & $2.82 \%$ & $25.31 \%$ & $71.87 \%$ \\
\hline North China (A6) & $0.95 * *$ & $0.86 \%$ & $19.79 \%$ & $0.00 \%$ & $80.34 \%$ & $16.79 \%$ & $2.01 \%$ & $32.77 \%$ & $65.22 \%$ \\
\hline Middle to Lower & & & & & & & & & \\
\hline Reaches of Yangtze & $0.93 *$ & $1.76 \%$ & $19.06 \%$ & $0.00 \%$ & $81.01 \%$ & $16.06 \%$ & $3.26 \%$ & $28.94 \%$ & $67.80 \%$ \\
\hline River (A7) & & & & & & & & & \\
\hline South China (A8) & $1.31 * *$ & $2.43 \%$ & $17.25 \%$ & $0.00 \%$ & $83.08 \%$ & $27.52 \%$ & $3.34 \%$ & $36.56 \%$ & $60.10 \%$ \\
\hline All & $0.40 * *$ & $2.95 \%$ & $26.52 \%$ & $20.78 \%$ & $52.76 \%$ & $9.35 \%$ & $5.68 \%$ & $21.22 \%$ & $73.10 \%$ \\
\hline
\end{tabular}

** indicates $p<0.01$; * indicates $p<0.05$. Pixels with slopes equal to 0 are located in areas with no vegetation cover. 
Consistent with previous studies, a greening trend was more widespread than a browning trend in China over the past few decades [5,17]. However, most areas in our study revealed stronger relationships than the results of earlier studies based on annual mean NDVI $[8,23]$. This may suggest that vegetation changes in China are more prevalent than previously predicted and growing-season NDVI may be more useful for detecting vegetation activities compared with the annual mean NDVI.
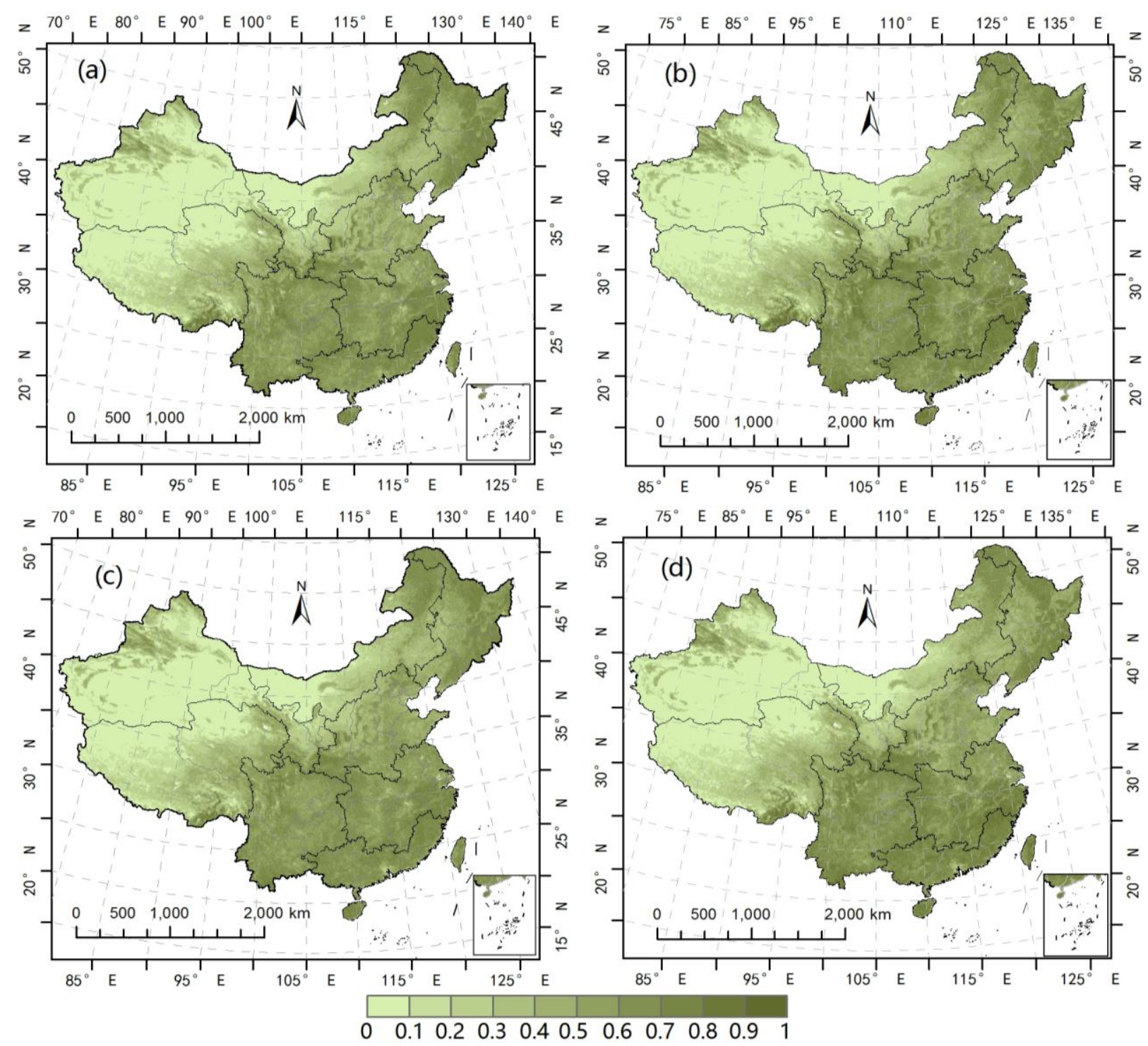

Figure 3. Spatial distribution of growing-season NDVI in 1982 (a), 1990 (b), 2000 (c), and $2011(\mathbf{d})$.

Growing-season NDVI increased more in low- and mid-latitudinal monsoon sub-regions (A5, A6, $\mathrm{A} 7$, and A8) compared with other areas, and a larger percentage of steep upward trends $\left(>0.002 \mathrm{yr}^{-1}\right)$ was measured in these sub-regions. The Yunnan-Guizhou Plateau, Jiangnan Hilly Region, and Qinling Mountain area are all distributed in these monsoon regions. The trend in Southwest China (A5) was not significant even though the value was high, possibly because of large climate variability and fluctuations in the NDVI time series.

Growing-season NDVI in 1982, 1990, 2000, and 2011 are shown in Figure 3. Great change could be found in different sub-regions over time from 1982 to 2011. In northern part of Northeast China (A1) 
and Inner Mongolia (A2), vegetation grew luxuriantly in 1982 and 1990, while large area showed vegetation degradation in 2000 and 2011. In Middle to Lower Reaches of Yangtze River (A7), Southwest China (A5) and South China (A8), even though growing-season NDVI was originally high, large area exhibited vegetation improvement. More details could be found in results of linear trend (Figure 4).

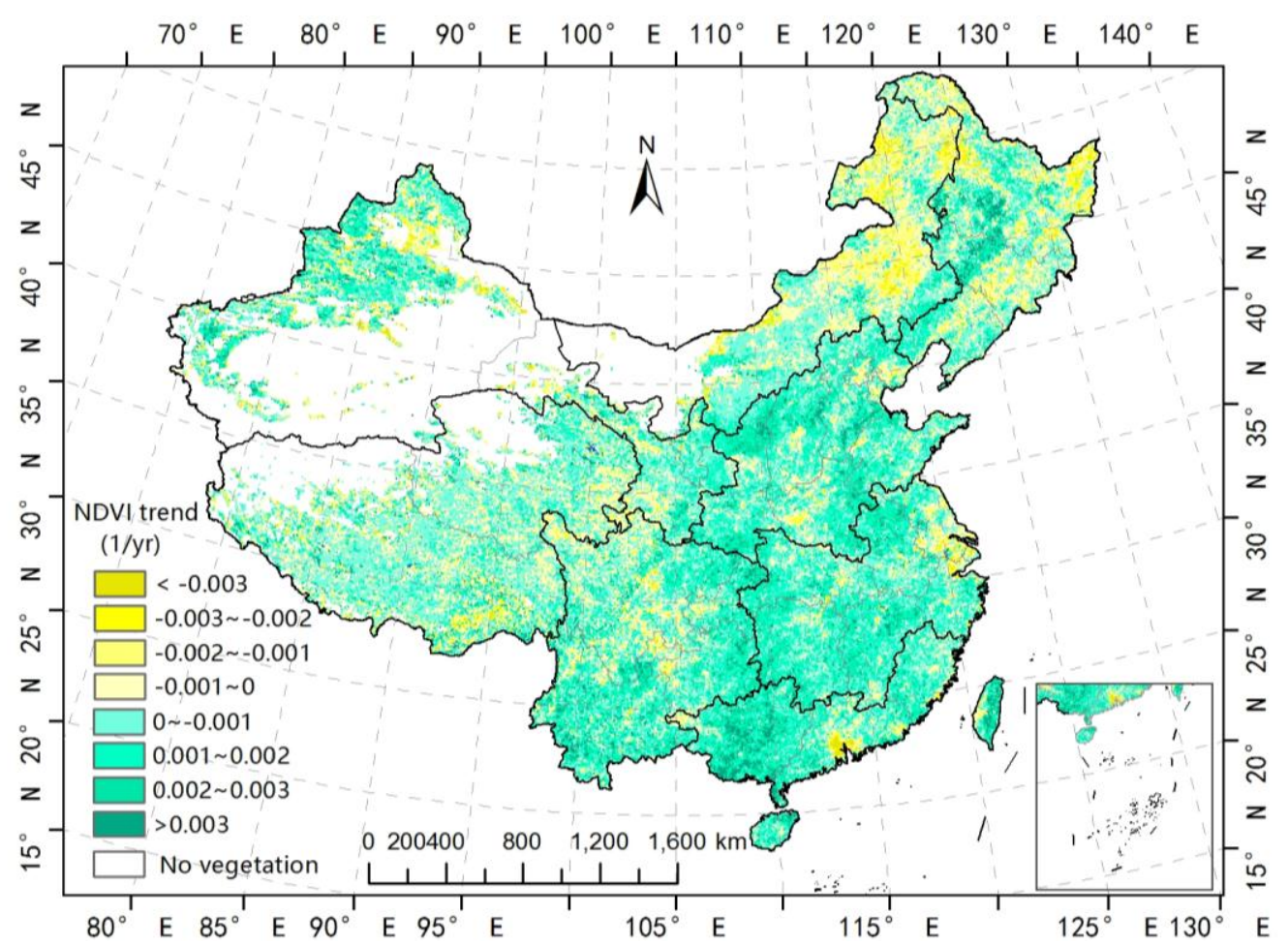

(a)

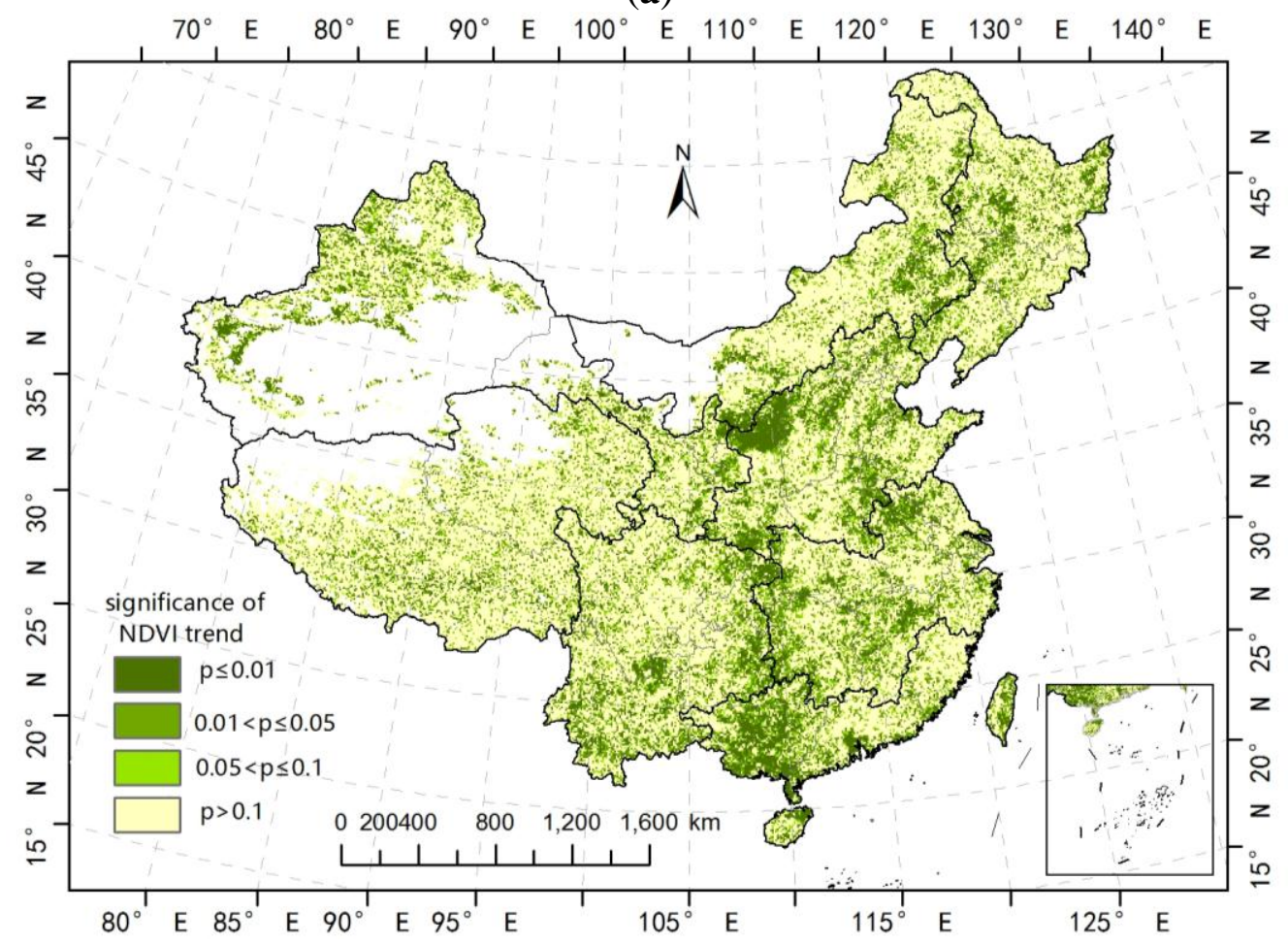

(b)

Figure 4. Growing-season NDVI trends (a) and their significance (b) from 1982 to 2011 in China. 
As shown in Figure 4a, positive trends in growing-season NDVI were found in the North China Plain, Northeast China Plain, and Loess Plateau, as well as in some areas of the Middle Lower Yangtze Plain, in which large area showed significant change (Figure 4b). Vegetation in these four regions mainly consists of cultivated crops. The improved agricultural practices may partly explain the increased NDVI, as irrigation and fertilizer use had increased in the past several decades [37].

Large areas $(9.81 \%$ and $12.20 \%$, respectively) with significant negative trends existed in Northeast China (A1) and Inner Mongolia (A2), which is located in the northern-most part of China (Table 2). As shown in Figure 4a,b, within these two sub-regions, growing-season NDVI decreased significantly in most areas of the Inner Mongolia Grassland, Greater Hinggan, Lesser Hinggan, and Changbai Mountain regions. A similar pattern of vegetation changes was found in these areas using the growing season (defined as the period from April to October) NDVI [43], as well as the annual NDVI [62]. However, the significance of these trends was weaker than that in our study, which may suggest that the growing season extracted by our algorithm is more effective than the approximately defined growing season used in the study by Jiang et al. [43].

Steep negative trends were found in the Yangtze River Delta, Pearl River Delta, and Beijing-Tianjin region (Figure 4a,b). As discussed in some previous studies, there is evidence of sharp NDVI decrease in these regions [8,23,43], possibly due to rapid urbanization [18].

\subsection{Effects of Climate Variables on Vegetation Variations}

The multiple linear regression models achieved low RMSEs and varied by <3\% among regions (Table 3) and by $<10 \%$ among most pixels (Figure 5). The most influential factors were defined as the largest absolute value of the variable coefficients (CES).

Table 3. Coefficients (CES) of multiple regression models in each sub-region $\left(10^{-3}\right)$.

\begin{tabular}{ccccccccc}
\hline Factor & $\mathbf{A 1}$ & $\mathbf{A 2}$ & $\mathbf{A 3}$ & $\mathbf{A 4}$ & $\mathbf{A 5}$ & $\mathbf{A 6}$ & $\mathbf{A 7}$ & $\mathbf{A 8}$ \\
\hline P1 & -0.74 & $\underline{4.78}$ & 1.92 & -1.50 & -0.89 & 1.60 & $-\underline{4.42}$ & -4.72 \\
P2 & $\underline{4.01}$ & 0.30 & -0.85 & $\underline{3.25}$ & -1.41 & 7.98 & -1.90 & 1.79 \\
P3 & 3.44 & -0.22 & 2.17 & -0.13 & 1.84 & $\underline{10.79}$ & -0.47 & -1.20 \\
P4 & 2.52 & 1.41 & 0.00 & -0.73 & -0.16 & -0.81 & 3.29 & -0.01 \\
T1 & -0.04 & 2.05 & $\underline{2.39}$ & 2.87 & 3.04 & 4.36 & 3.50 & $\underline{6.49}$ \\
T2 & 0.22 & -1.61 & -2.07 & -0.88 & $\underline{4.42}$ & 3.14 & 0.57 & -0.77 \\
T3 & 0.86 & -0.39 & 0.55 & 0.38 & 0.96 & 0.67 & 4.36 & 3.27 \\
T4 & 0.92 & 1.83 & 0.80 & -1.85 & 2.19 & 0.34 & 1.90 & 1.75 \\
B & 608.65 & 332.97 & 137.49 & 214.86 & 637.76 & 513.91 & 651.67 & 659.13 \\
Slope (predicted & 0.06 & -0.14 & 0.11 & 0.18 & 0.63 & 0.80 & 0.66 & 0.39 \\
NDVI) & & & & & & & & \\
RMSE & 9.84 & 5.93 & 3.86 & 5.63 & 11.63 & 10.67 & 16.05 & 19.12 \\
RMSE (\%) & $1.62 \%$ & $1.78 \%$ & $2.81 \%$ & $2.62 \%$ & $1.82 \%$ & $2.08 \%$ & $2.46 \%$ & $2.90 \%$ \\
\hline
\end{tabular}

Underline highlights the highest absolute coefficient value. P1, P2, P3, and P4 indicate the total precipitation during the current growing season, previous growing season, Stage 2, and Stage 1, respectively, and T1, T2, T3, and T4 indicate the mean temperature during these same periods, respectively. 


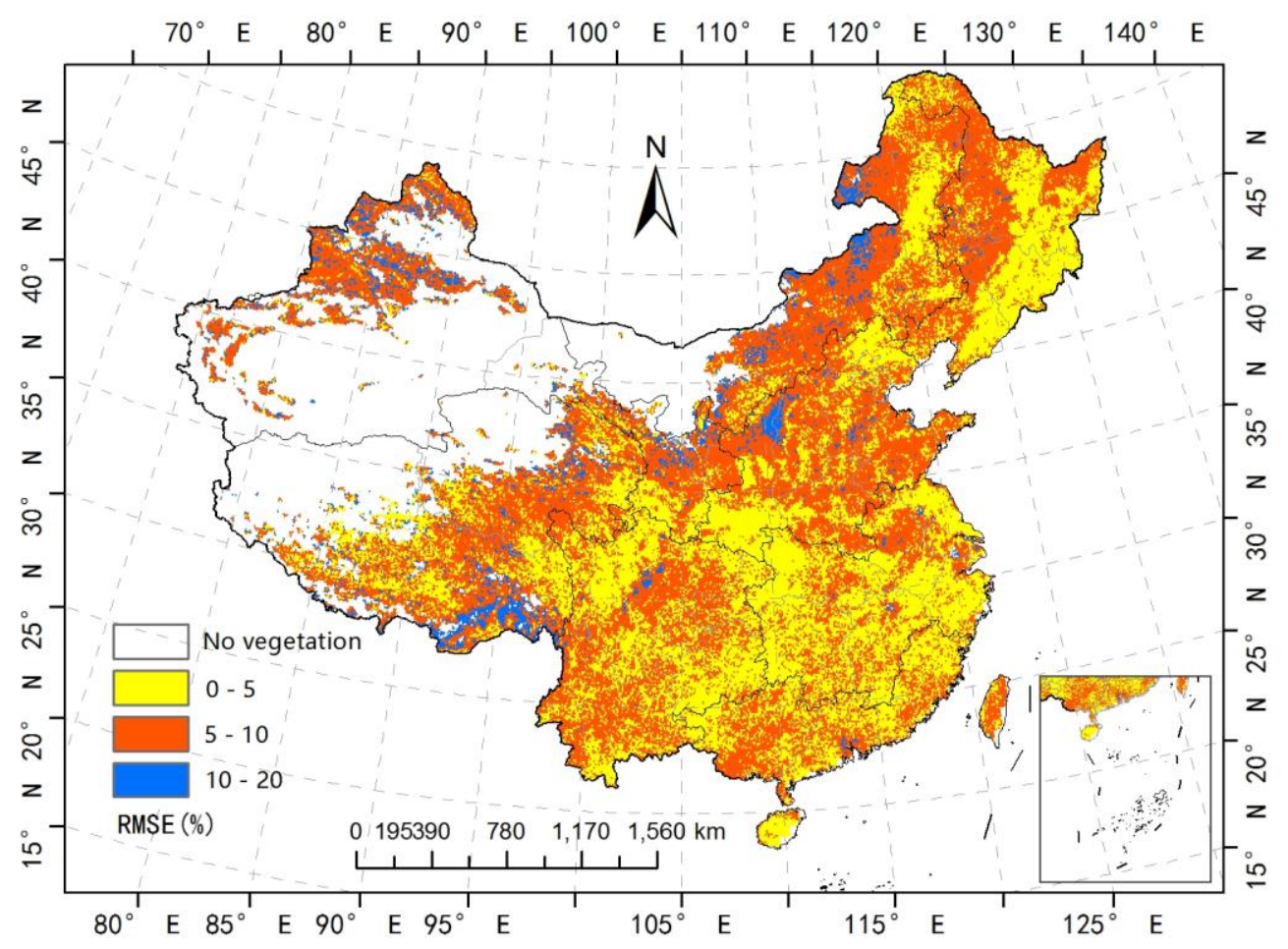

Figure 5. Spatial distribution of Root Mean Square Error (RMSE) in multiple linear regression models.

Table 3 shows the results of the models for each sub-region. Xiao and Moody (2004) suggested that temperature contributes more than precipitation to the greening pattern of most types of vegetation in the northern to middle regions of China [17]. Furthermore, other studies have shown that NDVI is positively related to temperature [14,19,21], and similar conclusions can be drawn from our investigation. Compared to P1, the current growing season temperature (T1) had a stronger effect on growing-season NDVI in all sub-regions except Northeast China (A1).

However, the interactions between vegetation and climatic factors are more complex than proposed in some other studies, and the lag between climatic factors and NDVI requires attention. The large differences among regional climatic conditions may be influenced by these interactions, and thus they should be carefully investigated. More details are given in following paragraphs, and the main factors as well as other strong factors (those with high absolute coefficient values) are also discussed.

(1) In general, precipitation has a significant positive influence on vegetation in arid and semi-arid areas, whereas increasing temperature can restrict vegetation growth $[23,24]$ as a result of accelerated water evaporation [63]. In Inner Mongolia (A2), P1 (Ce =4.78) was the strongest explanatory factor for vegetation variations, consistent with previous studies $[28,29,34]$. Similarly, in Northwest China (A3), P1 (Ce = 1.92) and $\mathrm{P} 3(\mathrm{Ce}=2.17)$ also benefited vegetation growth by improving the insufficient water supply.

However, the conclusions drawn in this study suggest a slightly more complex scenario. Growing-season NDVI was impacted by concurrent temperature variations (T1) in Northwest China (A3). This was probably because the studied areas were at high altitude and the increased temperature was favorable to vegetation growth in cold conditions. The same reason may explain the strong positive effect of T1 on NDVI in the Tibetan Plateau (A4) and Inner Mongolia (A2), of which the Ce was 2.87 and 2.05, respectively. 
(2) In the monsoon areas, even though the results exhibited high special heterogeneity, there are numerous possible interactions between growing-season NDVI and various climatic factors. For example, more precipitation in humid regions is associated with increased cloudiness and water retention, and can even result in floods [18]. Thus, P1 had a strong negative effect on growing-season NDVI in Southwest China (A8) $(\mathrm{Ce}=-4.42)$ and the Middle to Lower Reaches of the Yangtze River (A7) $(\mathrm{Ce}=-4.72)$, as well as a negative (but less strong) effect in Southwest China (A5) $(\mathrm{Ce}=-0.89)$ and Northeast China (A1) ( $\mathrm{Ce}=-0.74)$.

In contrast to the other sub-regions, the average temperature during Stage 2 (T3) significantly improved vegetation growth in Southwest China (A8) $(\mathrm{Ce}=3.27)$ and the Middle to Lower Reaches of the Yangtze River (A7) $(\mathrm{Ce}=4.36)$, revealing the strong lag effect between temperature and growing-season NDVI. As most vegetation in these regions consists of evergreens and the length of growing season is $\sim 10$ months, winter temperature is also very important to vegetation in subtropical regions of China.

In Northeast China (A1), it was very unusual that P3 $(\mathrm{Ce}=3.44), \mathrm{P} 4(\mathrm{Ce}=2.52)$, and especially P2 $(\mathrm{Ce}=4.01)$ largely impacted growing season growth compared to temperature. This could suggest that more water stored during the previous growing season was conducive to plant growth in the next year. In addition, as precipitation during the withering season (P3 and P4) was mainly in the form of snow in Northeast China (A1), snow prevented plants from freeze injury and melted to provide water for the next growing season.

Unusual interactions between vegetation and climatic factors were also seen in North China (A6), which is the main farming area in China. The factors $\mathrm{P} 2(\mathrm{Ce}=7.98)$ and $\mathrm{P} 3(\mathrm{Ce}=10.79)$, as well as T1 $(\mathrm{Ce}=4.36)$ and $\mathrm{T} 2(\mathrm{Ce}=3.14)$, positively influenced vegetation growth. However, these interactions may have been induced by human activities.

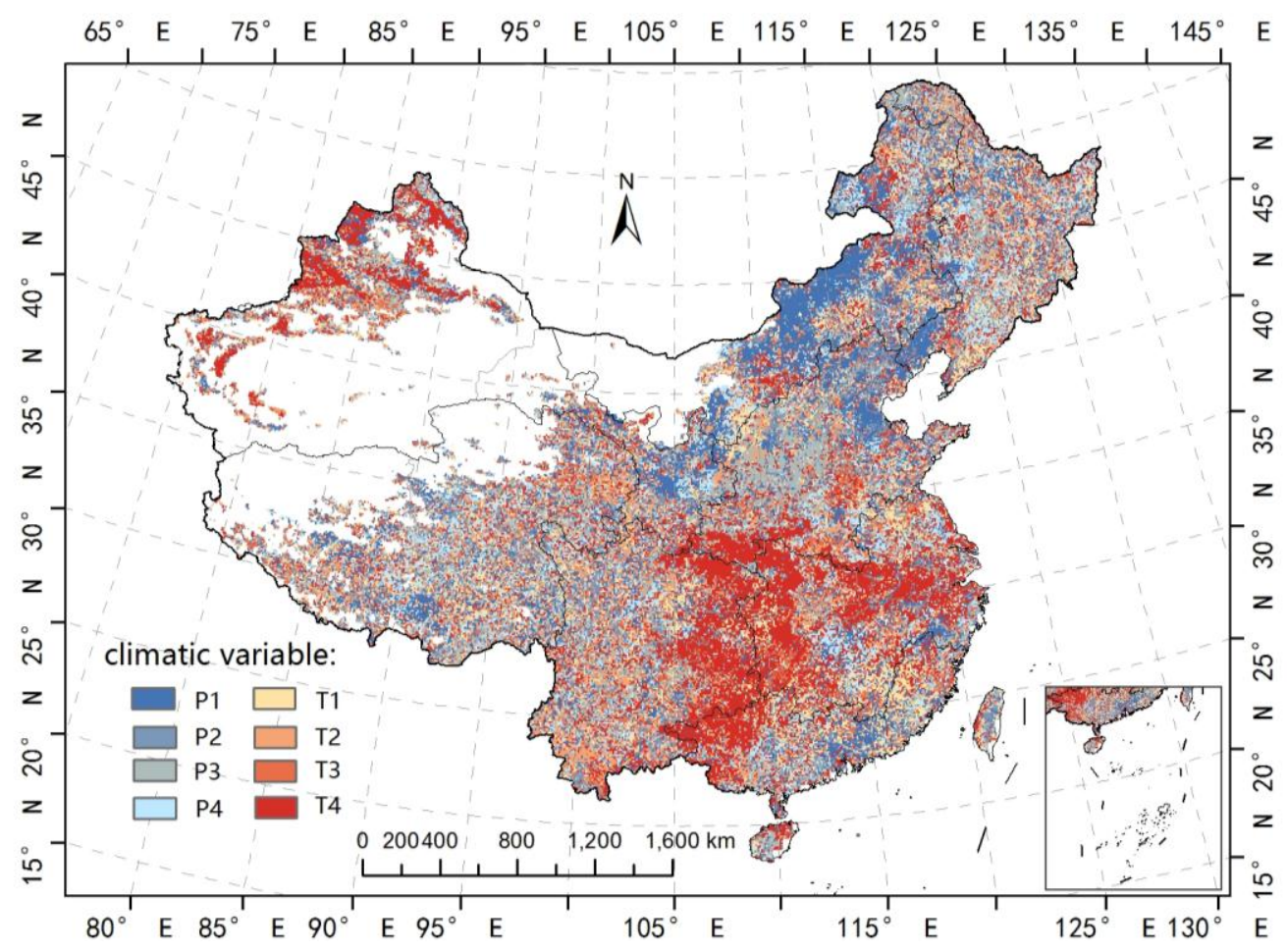

Figure 6. Spatial distribution of the main climatic variables affecting growing-season NDVI. P1, P2, P3, and P4 indicate the total precipitation during the current growing season, previous growing season, Stage 2, and Stage 1, respectively, and T1, T2, T3, and T4 indicate the mean temperature during these same periods, respectively. 
Figure 6 shows the main factors as pixels. Compared with temperature, precipitation was a more important factor for growing-season NDVI in the northern regions of the study area, including Northeast China (A1), Inner Mongolia (A2), North China (A6), and the southeast part of Northwest China (A3). However, temperature was a stronger factor in Southwest China (A5), the Middle to Lower Reaches of the Yangtze River (A7), South China (A8), and the northwest part of Northwest China (A3). The results also indicate that $\mathrm{P} 1$ influenced vegetation growth over a widespread area, covering the central area of Inner Mongolia (A2), southeast area of Northwest China (A3), and northern area of North China (A6). In addition, $\mathrm{P} 3$ had a strong effect on vegetation growth in the western part of A1, as well as some scattered areas throughout Northeast China (A1), the Tibetan Plateau (A4), and Southwest China (A5). With respect to temperature, T4 had the strongest impact on growing-season NDVI, particularly in the transitional regions of Southwest China (A5), the Middle to Lower Reaches of the Yangtze River (A7), and South China (A8).

\subsection{Effects of Human Activities on Vegetation Variations}

The trend distribution of the model residuals is described in Figure 7a, and the results of significance tests are shown in Figure 8 spatially and in Table 4 statistically. To introduce the model residuals analysis, a micro-region in Inner Mongolia (A2) was selected in Figure 7a. In this micro-region, a positive trend was found in the left part of this region, whereas the right side displayed the opposite behavior. Then linear regression of the model residuals was analyzed in detail in the western and eastern areas of this micro-region, as described in Figure 7e,d, respectively. The differences between remotely sensed and model-predicted NDVI values in this micro-region are also shown in Figure 7c. Table 5 shows the land-use change between 1990 and 2005.

The results in Figure 8 suggest that a great deal of the study area experienced human-induced changes from 1982 to 2011, and about $6 \%$ of the study area was significantly disturbed by human activities (Table 4).

Table 4. Significance of slopes in sub-regions.

\begin{tabular}{|c|c|c|c|c|c|}
\hline \multirow[t]{2}{*}{ Region } & \multicolumn{2}{|c|}{$\begin{array}{l}\text { Significantly Declined } \\
\qquad(p<0.05)\end{array}$} & \multicolumn{2}{|c|}{$\begin{array}{l}\text { Significantly Increased } \\
(p<0.05)\end{array}$} & \multirow{2}{*}{$\begin{array}{c}\begin{array}{c}\text { No } \\
\text { Significance }\end{array} \\
\text { Proportion }\end{array}$} \\
\hline & Proportion & $\begin{array}{c}\text { Area } \\
\left(10^{3} \mathrm{~km}^{2}\right)\end{array}$ & Proportion & $\begin{array}{c}\text { Area } \\
\left(10^{3} \mathrm{~km}^{2}\right)\end{array}$ & \\
\hline Northeast China (A1) & $2.02 \%$ & 16.90 & $6.94 \%$ & 57.92 & $91.04 \%$ \\
\hline Inner Mongolia (A2) & $0.58 \%$ & 5.31 & $2.70 \%$ & 24.83 & $96.72 \%$ \\
\hline Northwest China (A3) & $1.13 \%$ & 9.22 & $4.52 \%$ & 36.86 & $94.36 \%$ \\
\hline Tibetan Plateau (A4) & $1.00 \%$ & 10.75 & $0.93 \%$ & 10.05 & $98.07 \%$ \\
\hline Southwest China (A5) & $1.24 \%$ & 11.78 & $6.33 \%$ & 60.10 & $92.43 \%$ \\
\hline North China (A6) & $0.81 \%$ & 6.72 & $3.68 \%$ & 30.46 & $95.51 \%$ \\
\hline Middle to Lower Reaches of Yangtze River (A7) & $1.90 \%$ & 14.78 & $2.09 \%$ & 16.32 & $96.01 \%$ \\
\hline South China (A8) & $1.39 \%$ & 6.66 & $18.71 \%$ & 89.60 & $79.90 \%$ \\
\hline All & $1.23 \%$ & 82.112 & $4.88 \%$ & 326.144 & $93.89 \%$ \\
\hline
\end{tabular}




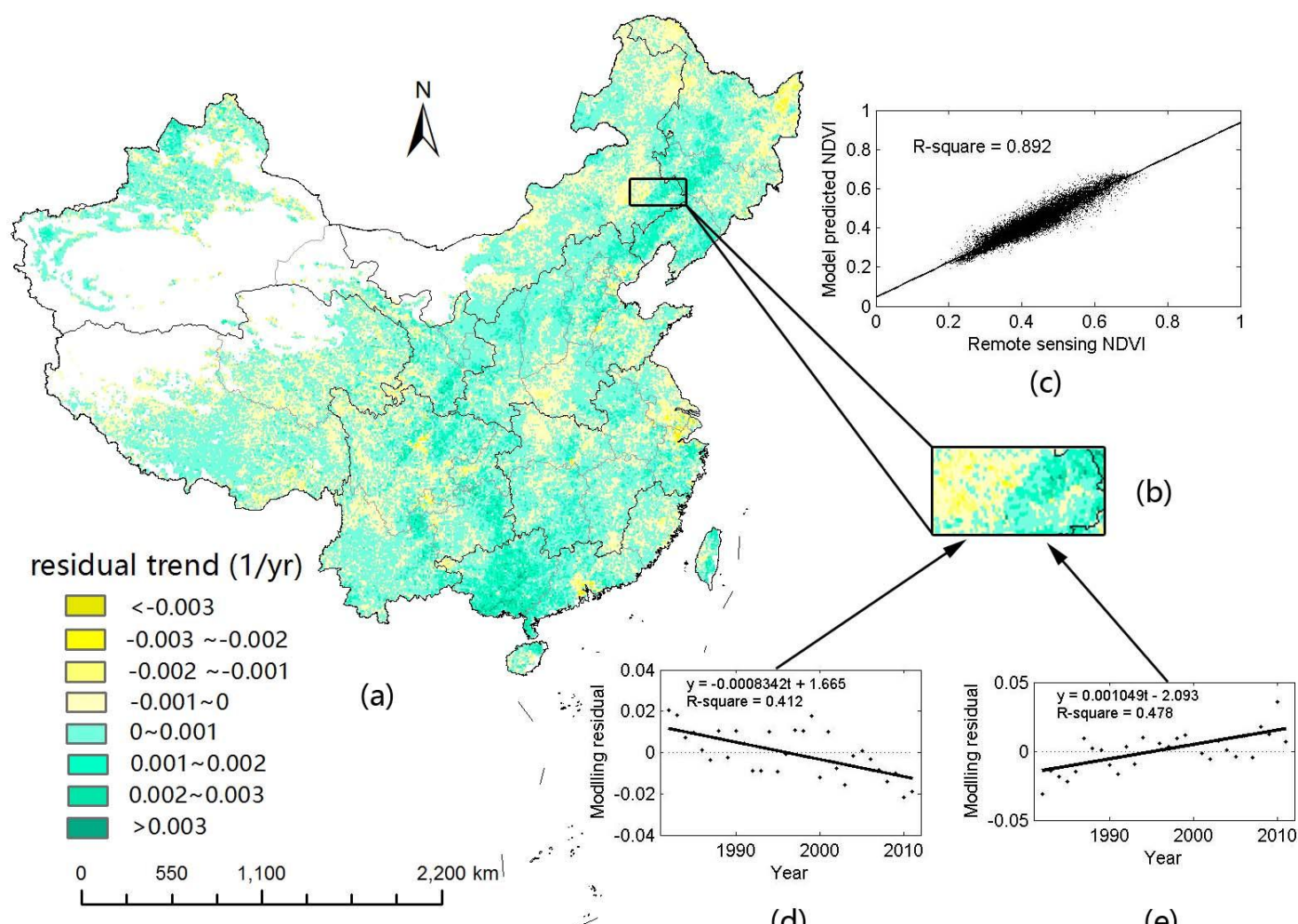

(d)

(e)

Figure 7. (a) Spatial distribution of residual slopes from 1982 to 2011 in China. (b) Micro-region of A2 with a striking contrast in slopes. (c) Differences between remotely sensed and model-predicted NDVI values in this micro-region. Linear regression of residuals in the (d) western and (e) eastern areas of the micro-region.

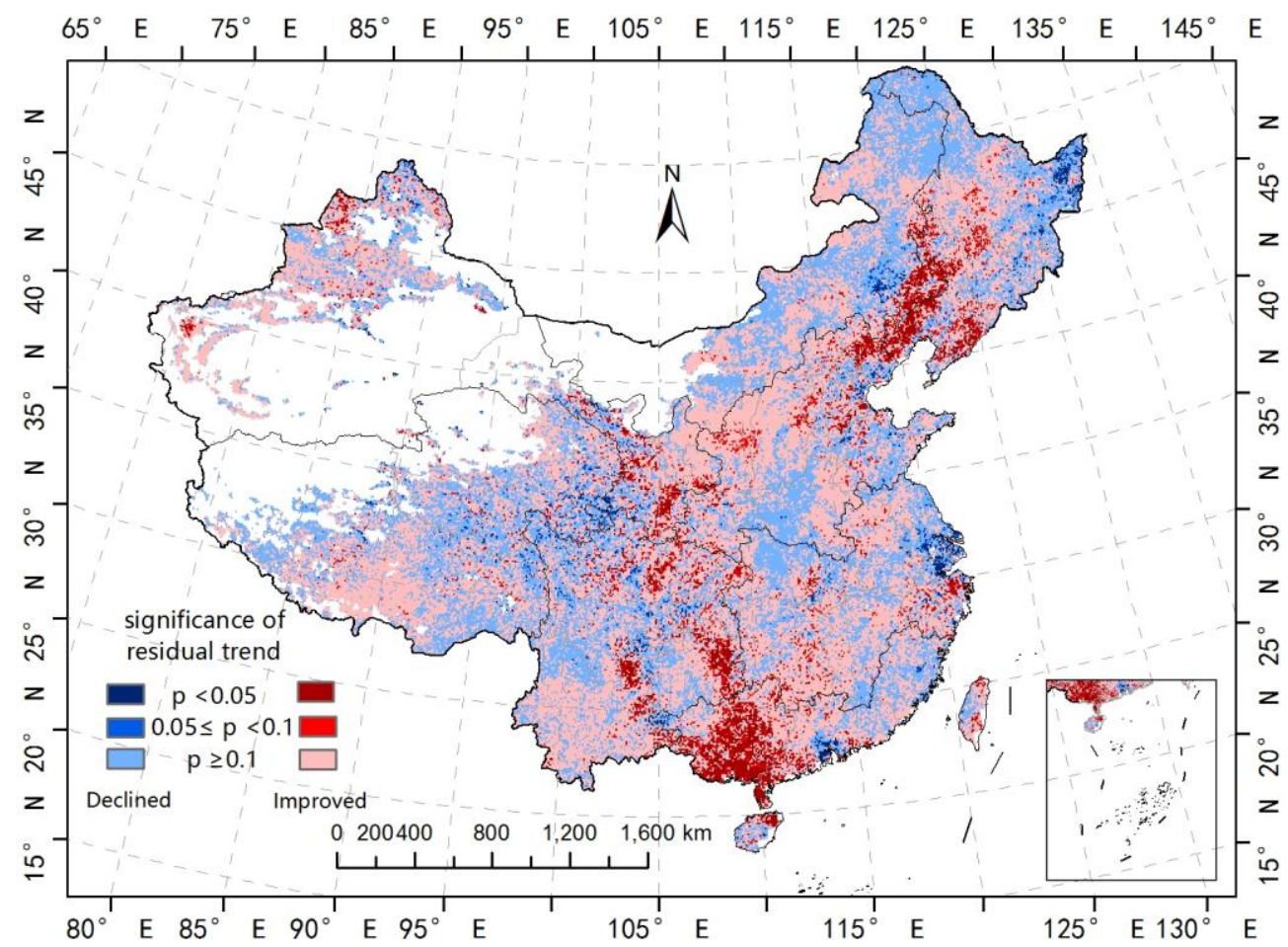

Figure 8. Significance of slopes of linear regression residuals based on $t$-tests. 
Areas experiencing human-induced vegetation degradation (Figure 8) were largely distributed in the Yangtze River Delta and Pearl River Delta. Along with the rapid development of the Chinese economy over the past three decades, cities expanded into croplands and woodlands in these regions, resulting in vegetation degradation. As seen from the land-use change (Table 5), built-up areas in China increased sharply in 2005. The construction of buildings and roads may explain the vegetation degradation in some urban and suburban areas, particularly in North China (A6), the Middle to Lower Reaches of the Yangtze River (A7), and South China (A8).

Table 5. Land-use change from 1990 to $2005\left(10^{3} \mathrm{~km}^{2}\right)$.

\begin{tabular}{ccccccc}
\hline Region & Cropland & Woodland & Grassland & $\begin{array}{c}\text { Water } \\
\text { Bodies }\end{array}$ & $\begin{array}{c}\text { Built-up } \\
\text { Area }\end{array}$ & $\begin{array}{c}\text { Unused } \\
\text { Land }\end{array}$ \\
\hline Northeast China (A1) & 26.20 & -11.17 & -9.47 & -1.79 & 0.94 & -4.71 \\
Inner Mongolia (A2) & 10.90 & -2.72 & -11.73 & -0.57 & 0.73 & 3.39 \\
Northwest China (A3) & 11.97 & 2.56 & -12.10 & 2.96 & 1.63 & -7.01 \\
Tibetan Plateau (A4) & 0.17 & -0.21 & -1.20 & 0.52 & 0.37 & 0.34 \\
Southwest China (A5) & -2.83 & -0.63 & 1.64 & -0.09 & 1.80 & 0.11 \\
North China (A6) & -8.89 & 1.74 & -1.45 & 0.84 & 10.17 & -2.41 \\
Middle to Lower Reaches & -10.72 & -0.10 & -0.41 & 2.73 & 8.84 & -0.34 \\
of Yangtze River (A7) & & & & & & \\
South China (A8) & -5.06 & 1.55 & -3.67 & 0.86 & 6.35 & -0.04 \\
All & 21.74 & -8.98 & -38.40 & 5.47 & 30.83 & -10.67 \\
\hline
\end{tabular}

The Sanjiang Plain (in Northeast China (A1)) region also suffered from human-induced degradation (Figure 8). Some studies have illustrated that agricultural activities have led to a reduction in wetlands over the past few decades and are an enormous threat to natural wetland vegetation [64]. Wetlands in the Sanjiang Plain were largely transformed into cropland over the period from 1990 to 2005 (Figure 9). The expansion of cropland also occurred in other sub-regions such as Northeast China (A1), Inner Mongolia (A2), and Northwest China (A3) (Table 5), resulting in vegetation degradation. In addition, there was considerable scatter throughout the southeastern part of the Da Hinggan Ling forest region of Inner Mongolia (A2), possibly due to deforestation.

Regions with significant human-induced improvement can also be seen in Figure 8. Large areas throughout the Kerqin Sandy Land and the Yanshan Mountain regions were strongly affected by human activities during the study period. Kerqin Sandy Land, a transition zone between the Inner Mongolian Plateau and the Northeast Plains, has suffered from severe desertification since the 1970s [65]. To reduce the influence of desertification on grasslands and croplands, the Chinese government has successfully developed and implemented measures for restoring desertified land [66]. Human-induced improvement also occurred in western South China (A8), which could be due to the forest conservation and planting policies adopted in karst areas of China. For the same reasons as above, natural forests in the Changbai Mountain area (eastern part of Northeast China (A1)) have been dramatically preserved and improved. 


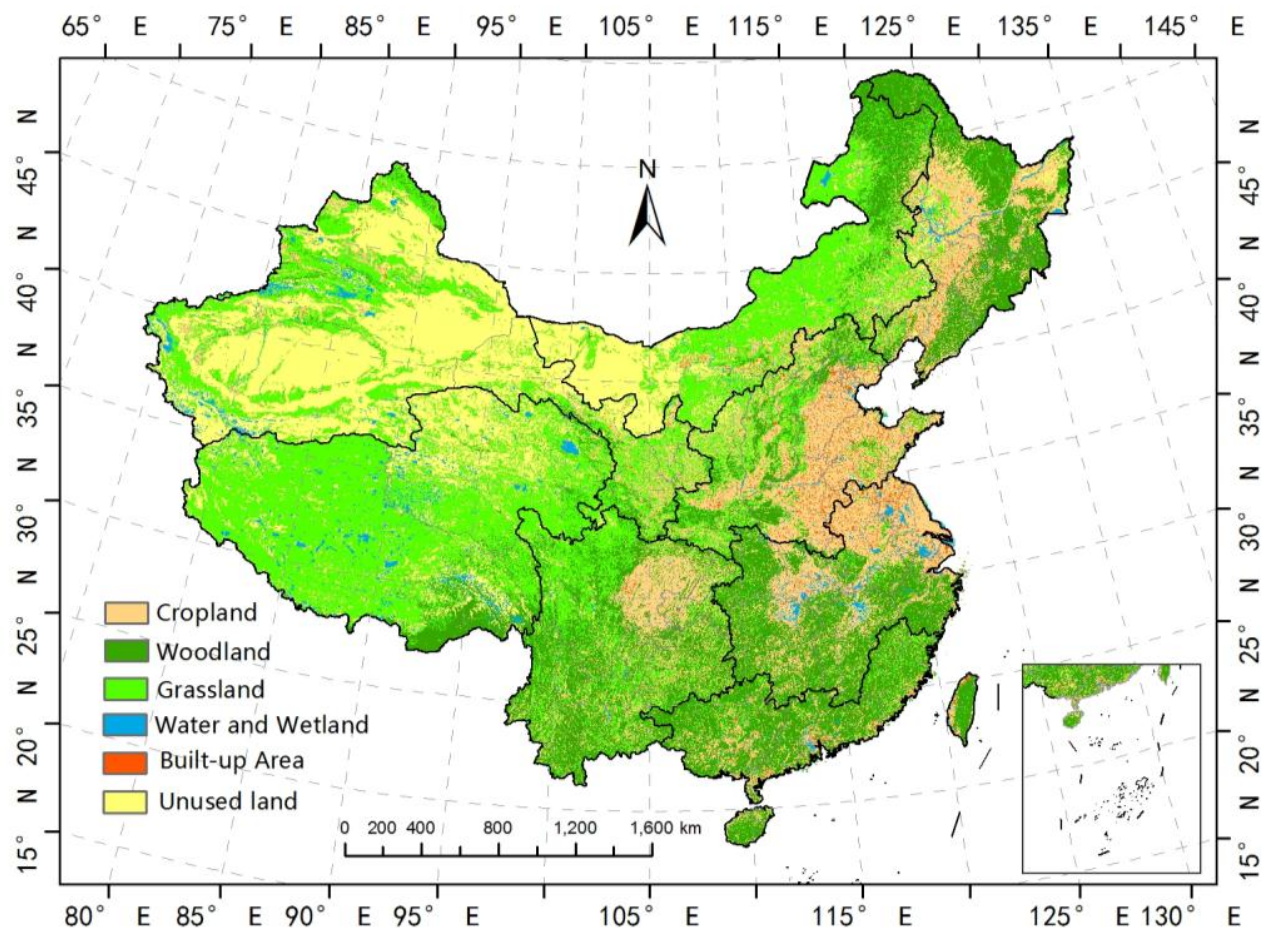

(a) 1990

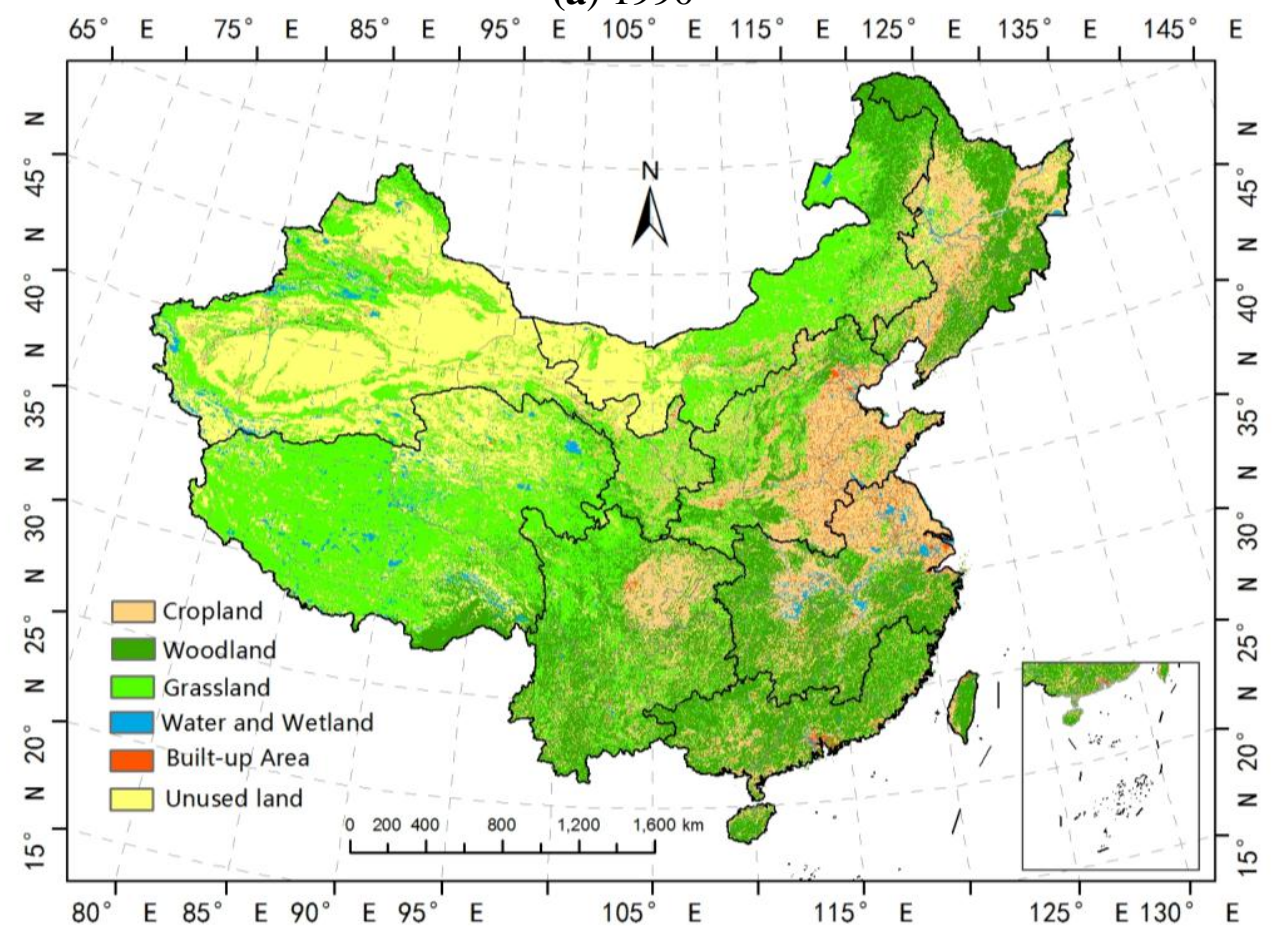

(b) 2005

Figure 9. Land-cover in China: 1990 (a) and 2005 (b).

In 1979, the central government of China decided to combat severe environmental degradation, including declining vegetation cover and expanding desertification [38]. To support this goal, the Three-North Shelter Forest Program (TNSFP) was implemented in three mostly arid and semi-arid regions: Northwest China (A3), Northeast China (A1), and the junction zone between Inner Mongolia (A2) and North China (A6). The program was a huge ecological restoration project and resulted in significant vegetation improvements (Figure 8) in the middle part of the Greater Hinggan region, the 
central and western Loess Plateau, the Hexi Corridor, and other scattered areas nearby. Some evidence of this effort was also displayed by the change in land-use between 1990 and 2005 (Figure 9). Over the past thirty years, China has made great strides in boosting food production [37]. Restricted by limited arable land, Chinese agricultural growth has had to rely on yield improvements to overcome the pressure of population growth, urbanization, and industrialization. At the same time, agricultural practices such as irrigation, fertilization, and machinery have improved significantly [67]. These activities can be tracked by changes in growing-season NDVI. As shown in Figure 8, a large area in the Northeast China Plain (central part of Northeast China (A1)) experienced significant human-induced improvement. The northern and southern parts of the North China Plain, as well as some areas in the Sichuan Basin, were also strongly influenced by human activities over the past three decades. Crop growth improvements in these regions can be partly ascribed to agricultural practices.

Anthropogenic activities are regularly cited as among the primary causes of desertification in rangelands, though changes in vegetation cover are more subtle than would be the case for other, less arid areas [40]. In our study, because barren or sparsely vegetated areas showed instability in the multi-regression models, we ignored areas in which the yearly averaged NDVI was below 0.1 in our analysis. However, the vegetation degradation in some arid and semi-arid areas close to the desert such as the eastern part of Inner Mongolia (A2) and scattered regions throughout Northwest China (A3) and Tibetan Plateau (A4) may be explained by the reasons listed above because of the desert-like conditions of these rangelands.

\section{Conclusions}

A growing-season NDVI time series was used to analyze interannual vegetation trends over the past three decades. The results indicated that vegetation activities significantly varied in approximately $30 \%$ of the total study area, two-thirds of which showed a significant increase. Growing-season NDVI may be more useful for detecting interannual vegetation activity variations than the annual mean NDVI, which has been used in most previous studies. Generally, vegetation activity variations are driven by climate and human activities. However, more precise and reliable conclusions were drawn in this study.

(1) Variations in vegetation activities on the Earth's surface are mainly driven by climate variations, especially global warming. The results of this study revealed that the current growing season temperature has a strong effect on growing-season NDVI in most regions of China except Northeast China (A1). Precipitation generally had a positive impact on plant growth. However, excess rainfall was a limiting factor in humid regions such as the Middle to Lower Reaches of the Yangtze River (A7) and South China (A8).

In addition, precipitation and temperature were shown to simultaneously influence vegetation activity. The effects could be the same (e.g., in North China (A6) and Inner Mongolia (A2)) or opposite (e.g., in the Middle to Lower Reaches of the Yangtze River (A7) and South China (A8)).

(2) Many studies have mentioned that vegetation activities are affected by not only contemporary climate variations, but also previous climate variations, as a result of effects on soil water, nutrients, microbial activities, etc. These effects depend on regional climatic conditions. The lag effect between climate variations and growing-season NDVI revealed in this study requires attention in analyses of vegetation activities in China. Therefore, future studies should attach importance to climate variations 
during periods before the growing season or previous growing season, which may also strongly influence vegetation growth.

For example, the average temperature during Stage 2 largely increased vegetation growth in the Middle to Lower Reaches of the Yangtze River (A7) and South China (A8), revealing that winter temperature is important in subtropical regions of China. In Northeast China (A1), previous season precipitation ( $\mathrm{P} 3, \mathrm{P} 4$, and especially $\mathrm{P} 2)$ influenced vegetation growth during the growing season. This reveals the strong lag effect of precipitation and growing-season NDVI in Northeast China, which is characterized by plentiful precipitation and long winters.

Our results support the hypothesis that there is a lag between climate variations and its effects on plant growth. This study may provide information for agricultural management such as crop yield forecasts or fertilizer and irrigation recommendations.

(3) Although many previous studies have investigated the driving forces of vegetation activities, there are limited reports that adequately estimate human-induced changes, especially in China. Thus, we attempted to provide a more sufficient discussion of these issues by analyzing the residuals of the NDVI model and detecting land-use change.

A large area of China experienced human-induced vegetation changes from 1982 to 2011, especially densely populated areas. Therefore, urbanization rather than climate change was the cause of the strong vegetation degradation in the Yangtze River Delta and Pearl River Delta. Agricultural practices also exhibited a strong influence on vegetation changes, and the improvement of growing-season NDVI in the Northeast China Plain, North China Plain, and Sichuan Basin could be partly due to agricultural activities. In addition, we found evidence of deforestation, ecological restoration, etc. due to policies implemented by local or national governments (e.g., vegetation degradation in the Sanjiang Plain and Da Hinggan Ling forest region and vegetation improvements in Kerqin Sandy Land, the Changbai Mountains, and western South China).

The land-use change validated the above conclusions. Land-use change put enormous pressure on natural vegetation, and the expansion of built-up areas and cropland was the main reason for the decrease in woodlands, grasslands, and unused land from 1982 to 2011, and thus the changes in growing-season NDVI.

Despite the clearly drawn conclusions of this study, some uncertainties still exist. For example, residual noise in the NDVI dataset after the robust smoothing algorithm was applied and resampling error in the CRU dataset could have affected the RMSE of the multiple regressions. In addition, the land-cover dataset derived from the Landsat TM/ETM could have contained both classification and aggregation errors [17].

Some aspects that were not fully considered here require further research. First, though global warming has been reported as the main reason for the recent vegetation greening pattern [14,19], human-induced changes may be concealed by the temperature increase in some areas. Thus, more effective models should be developed to amplify these parameters. Combination with a land-use change model that incorporates local land management might be a feasible way to do this. Second, the response of vegetation to climatic factors may vary among plant type. Moreover, climate variations over a period of more than two years may have a large impact on vegetation activities. Therefore, vegetation types and longer periods should be included in further analyses. Next, other climatic variables (e.g., water vapor, wind, and air pressure) and other factors (e.g., typhoons, cold waves, wildfires, and floods) may also 
greatly influence vegetation activities. Furthermore, $\mathrm{CO}_{2}$ fertilization effects and $\mathrm{N}$ enrichment and deposition may also partly impact vegetation changes. In spite of these shortcomings, our study significantly contributes to knowledge of vegetation activity variations and its driving factors in China.

\section{Acknowledgments}

This work was supported by the National Natural Science Foundation of China (No. 41471463), Important Science \& Technology Specific Projects of Qinghai Province (No. 2014-NK-A4-1).

\section{Author Contributions}

Aifeng Lv conceived the study. Bo Qu performed the data analysis and wrote the paper. Aifeng Lv, Wenbin Zhu and Shaofeng Jia read and modified the manuscript. All authors reviewed and approved the manuscript.

\section{Conflicts of Interest}

The authors declare no conflict of interest.

\section{References}

1. Wang, F.; Wang, X.; Zhao, Y.; Yang, Z. Temporal variations of NDVI and correlations between NDVI and hydro-climatological variables at Lake Baiyangdian, China. Int. J. Biometeorol. 2013, $58,1531-1543$.

2. Sims, D.A.; Rahman, A.F.; Cordova, V.D.; El-Masri, B.Z.; Baldocchi, D.D.; Bolstad, P.V.; Flanagan, L.B.; Goldstein, A.H.; Hollinger, D.Y.; Misson, L. A new model of gross primary productivity for North American ecosystems based solely on the enhanced vegetation index and land surface temperature from modis. Remote Sens. Environ. 2008, 112, 1633-1646.

3. Fensholt, R.; Rasmussen, K.; Nielsen, T.T.; Mbow, C. Evaluation of earth observation based long term vegetation trends-Intercomparing NDVI time series trend analysis consistency of Sahel from AVHRR GIMMS, TERRA MODIS and SPOT VGT data. Remote Sens. Environ. 2009, 113, 1886-1898.

4. Myneni, R.B.; Keeling, C.; Tucker, C.; Asrar, G.; Nemani, R. Increased plant growth in the northern high latitudes from 1981 to 1991. Nature 1997, 386, 698-702.

5. Kawabata, A.; Ichii, K.; Yamaguchi, Y. Global monitoring of interannual changes in vegetation activities using NDVI and its relationships to temperature and precipitation. Int. J. Remote Sens. 2001, 22, 1377-1382.

6. Los, S.O.; Collatz, G.J.; Bounoua, L.; Sellers, P.J.; Tucker, C.J. Global interannual variations in sea surface temperature and land surface vegetation, air temperature, and precipitation. J. Clim. 2001, $14,1535-1549$.

7. Chen, B.; Xu, G.; Coops, N.C.; Ciais, P.; Innes, J.L.; Wang, G.; Myneni, R.B.; Wang, T.; Krzyzanowski, J.; Li, Q.; et al. Changes in vegetation photosynthetic activity trends across the Asia-Pacific region over the last three decades. Remote Sens. Environ. 2014, 144, 28-41. 
8. Xu, G.; Zhang, H.; Chen, B.; Zhang, H.; Innes, J.L.; Wang, G.; Yan, J.; Zheng, Y.; Zhu, Z.; Myneni, R.B. Changes in vegetation growth dynamics and relations with climate over China's landmass from 1982 to 2011. Remote Sens. 2014, 6, 3263-3283.

9. White, M.A.; Beurs, D.; Kirsten, M.; Didan, K.; Inouye, D.W.; Richardson, A.D.; Jensen, O.P.; O'Keefe, J.; Zhang, G.; Nemani, R.R. Intercomparison, interpretation, and assessment of spring phenology in North America estimated from remote sensing for 1982-2006. Glob. Chang. Biol. 2009, 15, 2335-2359.

10. Braswell, B.; Schimel, D.; Linder, E.; Moore, B. The response of global terrestrial ecosystems to interannual temperature variability. Science 1997, 278, 870-873.

11. Horion, S.; Fensholt, R.; Tagesson, T.; Ehammer, A. Using Earth Observation-based dry season NDVI trends for assessment of changes in tree cover in the Sahel. Int. J. Remote Sens. 2014, 35, 2493-2515.

12. Liu, X.; Zhang, J.; Zhu, X.; Pan, Y.; Liu, Y.; Zhang, D.; Lin, Z. Spatiotemporal changes in vegetation coverage and its driving factors in the three-river headwaters region during 2000-2011. J. Geogr. Sci. 2014, 24, 288-302.

13. Xu, L.; Myneni, R.B.; Chapin, F.S., III; Callaghan, T.V.; Pinzon, J.E.; Tucker, C.J.; Zhu, Z.; Bi, J.; Ciais, P.; Tømmervik, H.; et al. Temperature and vegetation seasonality diminishment over northern lands. Nat. Clim. Chang. 2013, 3, 581-586.

14. Jeong, S.J.; Ho, C.H.; Gim, H.J.; Brown, M.E. Phenology shifts at start vs. end of growing season in temperate vegetation over the northern hemisphere for the period 1982-2008. Glob. Chang. Biol. 2011, 17, 2385-2399.

15. Cong, N.; Wang, T.; Nan, H.; Ma, Y.; Wang, X.; Myneni, R.B.; Piao, S. Changes in satellite-derived spring vegetation green-up date and its linkage to climate in China from 1982 to 2010: A multimethod analysis. Glob. Chang. Biol. 2013, 19, 881-891.

16. An, Y.; Gao, W.; Gao, Z. Characterizing land condition variability in northern China from 1982 to 2011. Environ. Earth Sci. 2013, 72, 663-676.

17. Xiao, J.; Moody, A. Trends in vegetation activity and their climatic correlates: China 1982 to 1998. Int. J. Remote Sens. 2004, 25, 5669-5689.

18. Piao, S. Interannual variations of monthly and seasonal normalized difference vegetation index (NDVI) in China from 1982 to 1999. J. Geophys. Res. 2003, 108, doi:10.1029/2002JD002848.

19. Tucker, C.J.; Slayback, D.A.; Pinzon, J.E.; Los, S.O.; Myneni, R.B.; Taylor, M.G. Higher northern latitude normalized difference vegetation index and growing season trends from 1982 to 1999. Int. J. Biometeorol. 2001, 45, 184-190.

20. Pettorelli, N.; Vik, J.O.; Mysterud, A.; Gaillard, J.-M.; Tucker, C.J.; Stenseth, N.C. Using the satellite-derived NDVI to assess ecological responses to environmental change. Trends Ecol. Evol. 2005, 20, 503-510.

21. Propastin, P.; Kappas, M.; Muratova, N. Inter-annual changes in vegetation activities and their relationship to temperature and precipitation in central Asia from 1982 to 2003. J. Environ. Inform. 2008, 12, 75-87.

22. Piao, S.; Mohammat, A.; Fang, J.; Cai, Q.; Feng, J. Ndvi-based increase in growth of temperate grasslands and its responses to climate changes in China. Glob. Environ. Change 2006, 16, 340-348. 
23. Meng, M.; Ni, J.; Zong, M. Impacts of changes in climate variability on regional vegetation in China: NDVI-based analysis from 1982 to 2000. Ecol. Res. 2011, 26, 421-428.

24. Song, Y.; Ma, M. A statistical analysis of the relationship between climatic factors and the normalized difference vegetation index in China. Int. J. Remote Sens. 2011, 32, 3947-3965.

25. Wang, J.; Rich, P.M.; Price, K.P. Temporal responses of NDVI to precipitation and temperature in the Central Great Plains, USA. Int. J. Remote Sens. 2003, 24, 2345-2364.

26. Nicholson, S.E.; Davenport, M.L.; Malo, A.R. A comparison of the vegetation response to rainfall in the Sahel and East Africa, using normalized difference vegetation index from NOAA AVHRR. Clim. Change 1990, 17, 209-241.

27. Xiao, X.; Ojima, D.S.; Parton, W.J.; Chen, Z.; Chen, D. Sensitivity of Inner Mongolia grasslands to climate change. J. Biogeogr. 1995, 22, 643-648.

28. Chuai, X.W.; Huang, X.J.; Wang, W.J.; Bao, G. NDVI, temperature and precipitation changes and their relationships with different vegetation types during 1998-2007 in Inner Mongolia, China. Int. J. Climatol. 2013, 33, 1696-1706.

29. Miao, L.; Ye, P.; He, B.; Chen, L.; Cui, X. Future climate impact on the desertification in the dry land Asia using AVHRR GIMMS NDVI3g data. Remote Sens. 2015, 7, 3863-3877.

30. Fabricante, I.; Oesterheld, M.; Paruelo, J. Annual and seasonal variation of NDVI explained by current and previous precipitation across northern Patagonia. J. Arid Environ. 2009, 73, 745-753.

31. Mueller, T.; Dressler, G.; Tucker, C.; Pinzon, J.; Leimgruber, P.; Dubayah, R.; Hurtt, G.; Böhning-Gaese, K.; Fagan, W. Human land-use practices lead to global long-term increases in photosynthetic capacity. Remote Sens. 2014, 6, 5717-5731.

32. Omuto, C.; Vargas, R.; Alim, M.; Paron, P. Mixed-effects modelling of time series NDVI-rainfall relationship for detecting human-induced loss of vegetation cover in drylands. J. Arid Environ. 2010, 74, 1552-1563.

33. Li, H.; Yang, X. Temperate dryland vegetation changes under a warming climate and strong human intervention-with a particular reference to the District Xilin Gol, Inner Mongolia, China. Catena 2014, 119, 9-20.

34. Tian, H.; Cao, C.; Chen, W.; Bao, S.; Yang, B.; Myneni, R.B. Response of vegetation activity dynamic to climatic change and ecological restoration programs in Inner Mongolia from 2000 to 2012. Ecol. Eng. 2015, 82, 276-289.

35. Savitzky, A.; Golay, M.J. Smoothing and differentiation of data by simplified least squares procedures. Anal. Chem. 1964, 36, 1627-1639.

36. Liu, Y.; Lu, S.; Chen, Y. Spatio-temporal change of urban-rural equalized development patterns in China and its driving factors. J. Rural. Stud. 2013, 32, 320-330.

37. Carter, C.A.; Zhong, F.; Zhu, J. Advances in Chinese agriculture and its global implications. Appl. Econ. Perspect. Policy 2012, 34, 1-36.

38. Duan, H.; Yan, C.; Tsunekawa, A.; Song, X.; Li, S.; Xie, J. Assessing vegetation dynamics in the three-north shelter forest region of China using AVHRR NDVI data. Environ. Earth Sci. 2011, 64, 1011-1020.

39. De Jong, R.; de Bruin, S.; de Wit, A.; Schaepman, M.E.; Dent, D.L. Analysis of monotonic greening and browning trends from global NDVI time-series. Remote Sens. Environ. 2011, 115, 692-702. 
40. Weiss, E.; Marsh, S.; Pfirman, E. Application of NOAA-AVHRR NDVI time-series data to assess changes in Saudi Arabia's rangelands. Int. J. Remote Sens. 2001, 22, 1005-1027.

41. Evans, J.; Geerken, R. Discrimination between climate and human-induced dryland degradation. $J$. Arid Environ. 2004, 57, 535-554.

42. Wessels, K.; Prince, S.; Malherbe, J.; Small, J.; Frost, P.; VanZyl, D. Can human-induced land degradation be distinguished from the effects of rainfall variability? A case study in South Africa. $J$. Arid Environ. 2007, 68, 271-297.

43. Jiang, N.; Zhu, W.; Zheng, Z.; Chen, G.; Fan, D. A comparative analysis between GIMSS NDVIg and NDVI3g for monitoring vegetation activity change in the northern hemisphere during 1982-2008. Remote Sens. 2013, 5, 4031-4044.

44. Chen, J.; Jönsson, P.; Tamura, M.; Gu, Z.; Matsushita, B.; Eklundh, L. A simple method for reconstructing a high-quality NDVI time-series data set based on the Savitzky-Golay filter. Remote Sens. Environ. 2004, 91, 332-344.

45. Hird, J.N.; McDermid, G.J. Noise reduction of NDVI time series: An empirical comparison of selected techniques. Remote Sens. Environ. 2009, 113, 248-258.

46. Roerink, G.; Menenti, M.; Verhoef, W. Reconstructing cloudfree NDVI composites using Fourier analysis of time series. Int. J. Remote Sens. 2000, 21, 1911-1917.

47. Jönsson, P.; Eklundh, L. TIMESAT -A program for analyzing time-series of satellite sensor data. Comput. Geosci. 2004, 30, 833-845.

48. Swets, D.L.; Reed, B.C.; Rowland, J.D.; Marko, S.E. A weighted least-squares approach to temporal NDVI smoothing. In Proceedings of the 1999 American Society for Photogrammetry and Remote Sensing (ASPRS) Annual Conference, Portland, OR, USA, 17-21 May 1999.

49. Harris, I.; Jones, P.; Osborn, T.; Lister, D. Updated highresolution grids of monthly climatic observations-The CRU TS3. 10 Dataset. Int. J. Climatol. 2014, 34, 623-642.

50. Ichii, K.; Kawabata, A.; Yamaguchi, Y. Global correlation analysis for NDVI and climatic variables and NDVI trends: 1982-1990. Int. J. Remote Sens. 2002, 23, 3873-3878.

51. Wu, D.; Wu, H.; Zhao, X.; Zhou, T.; Tang, B.; Zhao, W.; Jia, K. Evaluation of spatiotemporal variations of global fractional vegetation cover based on GIMMS NDVI data from 1982 to 2011. Remote Sens. 2014, 6, 4217-4239.

52. Keys, R. Cubic convolution interpolation for digital image processing. IEEE Trans. Acoust. 1981, 29, 1153-1160.

53. Liu, J.; Liu, M.; Tian, H.; Zhuang, D.; Zhang, Z.; Zhang, W.; Tang, X.; Deng, X. Spatial and temporal patterns of China's cropland during 1990-2000: An analysis based on Landsat TM data. Remote Sens. Environ. 2005, 98, 442-456.

54. Reed, B.C.; Brown, J.F.; VanderZee, D.; Loveland, T.R.; Merchant, J.W.; Ohlen, D.O. Measuring phenological variability from satellite imagery. J. Veg. Sci. 1994, 5, 703-714.

55. Beurs, K.M.D.; Henebry, G.M. Northern annular mode effects on the land surface phenologies of northern Eurasia. J. Clim. 2008, 21, 4257-4279.

56. Van Leeuwen, W.J. Monitoring the effects of forest restoration treatments on post-fire vegetation recovery with MODIS multitemporal data. Sensors 2008, 8, 2017-2042.

57. Moulin, S.; Kergoat, L.; Viovy, N.; Dedieu, G. Global-scale assessment of vegetation phenology using NOAA/AVHRR satellite measurements. J. Clim. 1997, 10, 1154-1170. 
58. Piao, S.; Fang, J.; Zhou, L.; Ciais, P.; Zhu, B. Variations in satellite-derived phenology in China's temperate vegetation. Glob. Chang. Biol. 2006, 12, 672-685.

59. Xin, J.; Yu, Z.; van Leeuwen, L.; Driessen, P.M. Mapping crop key phenological stages in the North China Plain using NOAA time series images. Int. J. Appl. Earth. Obs. Geoinf. 2002, 4, 109-117.

60. Tao, F.; Yokozawa, M.; Xu, Y.; Hayashi, Y.; Zhang, Z. Climate changes and trends in phenology and yields of field crops in China, 1981-2000. Agric. For. Meteorol. 2006, 138, 82-92.

61. Aiken, L.S.; West, S.G.; Reno, R.R. Multiple Regression: Testing and Interpreting Interactions; Sage Press: London, UK, 1991.

62. Wang, H.; Chen, A.; Wang, Q.; He, B. Drought dynamics and impacts on vegetation in China from 1982 to 2011. Ecol. Eng. 2015, 75, 303-307.

63. Jobbágy, E.G.; Sala, O.E.; Paruelo, J.M. Patterns and controls of primary production in the patagonian steppe: A remote sensing approach. Ecology 2002, 83, 307-319.

64. Wang, Z.; Zhang, B.; Zhang, S.; Li, X.; Liu, D.; Song, K.; Li, J.; Li, F.; Duan, H. Changes of land use and of ecosystem service values in Sanjiang Plain, Northeast China. Environ. Monit. Assess. 2006, 112, 69-91.

65. Zhang, T.H.; Zhao, H.L.; Li, S.G.; Li, F.R.; Shirato, Y.; Ohkuro, T.; Taniyama, I. A comparison of different measures for stabilizing moving sand dunes in the Horqin Sandy Land of Inner Mongolia, China. J. Arid Environ. 2004, 58, 203-214.

66. Li, Y.; Cui, J.; Zhang, T.; Okuro, T.; Drake, S. Effectiveness of sand-fixing measures on desert land restoration in Kerqin Sandy Land, Northern China. Ecol. Eng. 2009, 35, 118-127.

67. Nin-Pratt, A.; Yu, B.; Fan, S. Comparisons of agricultural productivity growth in China and India. J. Prod. Anal. 2010, 33, 209-223.

(C) 2015 by the authors; licensee MDPI, Basel, Switzerland. This article is an open access article distributed under the terms and conditions of the Creative Commons Attribution license (http://creativecommons.org/licenses/by/4.0/). 